Sādhanā Vol. 39, Part 6, December 2014, pp. 1523-1545. (C) Indian Academy of Sciences

\title{
Computation of gradually varied flow in compound open channel networks
}

\author{
H PRASHANTH REDDY ${ }^{1, *}$, M HANIF CHAUDHRY ${ }^{2}$ and \\ JASIM IMRAN ${ }^{2}$
}

${ }^{1}$ Department of Civil Engineering, Indian Institute of Technology Kharagpur, Kharagpur 721302, India

${ }^{2}$ Department of Civil and Environmental Engineering, University of South Carolina, Columbia, SC 29201, USA

e-mail: hpr@civil.iitkgp.ernet.in; chaudhry@cec.sc.edu; imran@cec.sc.edu

MS received 27 April 2014; revised 23 July 2014; accepted 6 August 2014

\begin{abstract}
Although, natural channels are rarely rectangular or trapezoidal in cross section, these cross sections are assumed for the computation of steady, gradually varied flow in open channel networks. The accuracy of the computed results, therefore, becomes questionable due to differences in the hydraulic and geometric characteristics of the main channel and floodplains. To overcome these limitations, an algorithm is presented in this paper to compute steady, gradually varied flow in an open-channel network with compound cross sections. As compared to the presently available methods, the methodology is more general and suitable for application to compound and trapezoidal channel cross sections in series channels, tree-type or looped networks. In this method, the energy and continuity equations are solved for steady, gradually varied flow by the Newton-Raphson method and the proposed methodology is applied to tree-type and looped-channel networks. An algorithm is presented to determine multiple critical depths in a compound channel. Modifications in channel geometry are presented to avoid the occurrence of multiple critical depths. The occurrence of only one critical depth in a compound cross section with modified geometry is demonstrated for a tree-type channel network.
\end{abstract}

Keywords. Gradually varied flow; open channel flow; compound channel networks; critical depth; steady flow; subcritical flows.

\section{Introduction}

Channel networks are ubiquitous in nature, such as braided river channels, divided shipping channels, interconnected storm water drainage systems and irrigation canals fed from different sources. The flow of water in an open channel can be treated as steady, gradually varied flow for

${ }^{*}$ For correspondence 
many practical purposes and a number of numerical techniques are available for the computation of these flows (Chow 1959; Chaudhry 2008). The standard step method based on single-step calculation is well-suited for a series channel system. The gradually varied flow computations are also required for the channel network or system of interconnected channels, such as the Indus Basin irrigation system, where the rivers are inter-connected through a number of large link canals. A number of researchers have studied unsteady flows in channel networks (Kutija 1995). More recently, Reddy \& Bhallamudi (2004) presented an algorithm for the computation of steady gradually varied flow in cyclic looped channel networks. The algorithm is based on computation in individual channel as initial value or boundary value problem and then determining a pair of linking channels by using the iterative Newton-Raphson technique for channel network.

Wylie (1972) developed an algorithm to compute the flow around a group of islands, in which the total length of the channel between two nodes is treated as a single reach to calculate the loss of energy and the node energy is used as a variable. In this method, the channel is not divided into several reaches as is done in a finite difference method. A reach is defined as the length of the channel between two finite-difference nodes. Chaudhry \& Schulte (1986a, b) presented a finite-difference method for the analysis of steady flow in a parallel channel system. Their formulation is in terms of the more commonly used variables, i.e., flow depths and discharges. Schulte \& Chaudhry (1987) later extended their method for application to general looped channel networks. In their method, a channel $i$ in the system is divided into several reaches, $N_{i}$. The continuity and energy equations can be written in terms of flow depths and flow rates for all the reaches, resulting in a total of $2 \sum_{i=1}^{i=M} N_{i}$ equations for $N_{i}+1$ nodes in any channel $i$ and there are $M$ channels in the system. Additional $2 M$ equations, required for closing the system, are obtained from the boundary conditions and the compatibility conditions at the junctions. The system of nonlinear simultaneous equations resulting from this formulation is solved by using the Newton-Raphson iteration technique. This requires inversion of the system Jacobian for every iteration step. In this formulation, the size of the Jacobian increases if the number of reaches in each channel is increased to improve accuracy. Sen \& Garg (2002) and Zhang \& Shen (2007) developed an efficient solution technique to compute GVF profiles for one-dimensional, steady and unsteady flow in a general channel network system with trapezoidal cross sections. Channels with trapezoidal cross-sections were considered in their studies by Schulte \& Chaudhry (1987), Reddy \& Bhallamudi (2004), Naidu et al (1997) to compute gradually varied flow in channel networks. However, if the channels have compound cross sections in both man-made and natural systems as in this case, the differences in hydraulic and geometric characteristics between the main channel and the overbank area needs to be accounted for.

The HEC-RAS model released by US Army Corps of Engineering can handle a single river reach, a dendritic network of channel system to model subcritical, super critical and mixed flow regime water surface profiles. However, the current version of steady flow model within HECRAS does not determine the amount of flow going to each reach at a flow split. Therefore, HEC-RAS cannot be used to networks where flow split is unknown at the junctions. Computation of critical depth is very important for the analysis of open channel flow because (i) gradually varied flow calculations are unstable near the critical depth, (ii) critical depth is a boundary condition at control points and (iii) critical depth is also required to verify the proper boundary condition for correct flow regime. A simple channel cross-section has only one critical depth for a given flowrate. However, multiple critical depths are associated with compound cross sections (Chaudhry \& Bhallamudi 1988). In compound channels, subcritical, critical and supercritical flows occur simultaneously. In this mixed flow regime, subcritical flow in main channel and critical or supercritical flows in flood plain is observed over a depth range (Kordi et al 2009). 
The entire cross section with mixed flow regime cannot be considered as a control section and resulting computations of water surface profile and designing of any controlling structure is very complicated. The occurrence of flow at critical regime of an open channel is highly unstable (Kordi et al 2009; Bhattacharjya 2006). Flow can be unstable if multiple critical depths occur in a channel section and it is important to design compound channels such that there is only one critical depth for a given discharge (Chaudhry \& Bhallamudi 1988). Two-dimensional flow features were observed in the flow between multiple critical depths (Blalock \& Sturm 1981, 1983; Sturm \& Sadiq 1996). Several authors (Knight \& Demetriou 1983; Ackers 1993; Bousmar \& Zech 1999; Kordi et al 2009) proposed momentum transfer and lateral flow between main channel and flood plains are significant and necessary to be considered in hydraulic computations. These effects are ambiguous and the results of the works of researchers have not yet yielded any comprehensive method for design and study about complex compound cross section and not yet been implemented in any commercial packages. Nevertheless, Sturm \& Sadiq (1996) obtained good agreement of computed water profiles with experimental data, for depths quite close to the critical ones by direct integration of the gradually varied flow equation and using a corrected Froude number.

The objective of the present research is to develop an efficient algorithm for computing gradually varied flow in open channel networks consisting of compound cross sections and develop criteria for design of compound channels in networks with a single critical depth. In this study, steady gradually varied flow in open channel networks with symmetric compound channel crosssections is considered. The methodology derived here is based on solving the continuity and the energy equations by using the Newton-Raphson method. The main advantages are its robustness and suitability for complex open channel networks.

\section{Methodology}

The following form of the energy equation can be applied between the two ends of a reach to compute water surface profile (Chaudhry 2008). Schematic of a compound channel cross section and reach between two cross sections are shown in figures 1 and 2.

$$
z_{1}+y_{1}+\frac{\propto_{1} Q_{t_{1}}^{2}}{2 g A_{t_{1}}^{2}}+h_{e}=z_{2}+y_{2}+\frac{\propto_{2} Q_{t_{2}}^{2}}{2 g A_{t_{2}}^{2}},
$$

where $z_{1}, z_{2}$ are elevations of the main channel invert levels; $y_{1}, y_{2}$ are depths of water at cross sections; $\propto_{1}, \propto_{2}$ are energy coefficients; $Q_{t_{1}}, Q_{t_{2}}$ are total discharges at sections 1 and $2 ; A_{t_{1}}$ and $A_{t_{2}}$ are total flow areas at sections 1 and $2 ; h_{e}$ is the head loss between two sections.

By neglecting expansion and contraction losses, the energy loss can be expressed as

$$
h_{e}=\Delta x \overline{S_{F}} .
$$

Average friction slope between two cross sections can be written as

$$
\overline{S_{F}}=\frac{S_{F_{1}}+S_{F_{2}}}{2}
$$

where $\Delta x=$ reach length; $\overline{S_{F}}=$ average friction slope between two sections, $S_{F_{1}}$ and $S_{F_{2}}$ are friction slopes at sections 1 and 2 . 


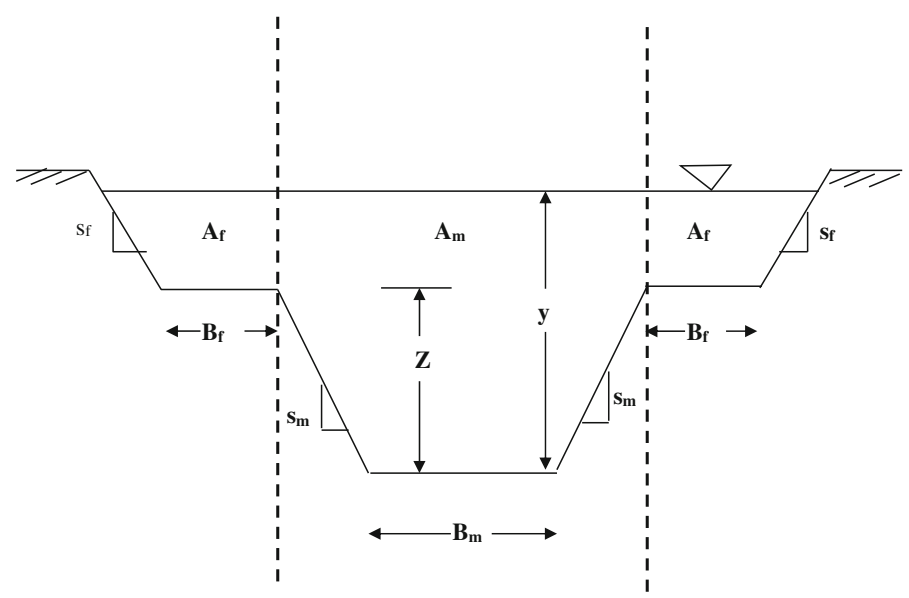

Figure 1. Schematic of compound cross section.

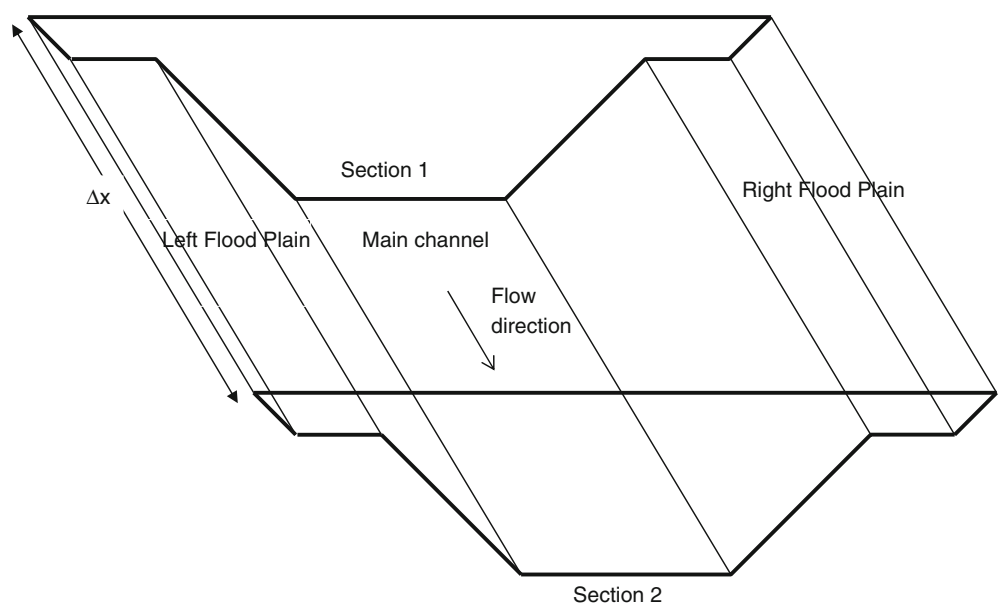

Figure 2. Geometry of symmetrical compound channel showing reach between cross sections 1 and 2 .

The discharge formula can be written as

$$
Q=K \sqrt{S_{F}},
$$

where $Q=$ discharge, $K=$ conveyance. The following equation is used to calculate conveyance at a cross section:

$$
K=\frac{1}{n} A R^{2 / 3}
$$

In the proposed divided channel method (DCM), compound channel conveyance is computed by the summation of main channel and floodplains conveyances. Total flow area $\left(\mathrm{m}^{2}\right)$, total discharge and total conveyance of the compound channel (figure 1) can be written as

$$
Q_{t}=2 Q_{f}+Q_{m}
$$




$$
\begin{gathered}
A_{t}=2 A_{f}+A_{m} \\
K_{t}=2 K_{f}+K_{m},
\end{gathered}
$$

where $Q_{t}, Q_{f}$ and $Q_{m}$ are total discharge, floodplain discharge, and discharge in main channel, respectively. Similarly, $A_{t}, A_{f}$ and $A_{m}$ denote total flow area of the compound channel, left or right flood plain flow area and flow area of main channel, respectively.

The energy coefficient $\propto$ is computed based on the conveyance in the three flow sub elements.

$$
\propto=\frac{A_{t}^{2}}{K_{t}^{3}}\left[\frac{2 K_{f}^{3}}{A_{f}^{2}}+\frac{K_{m}^{3}}{A_{m}^{2}}\right],
$$

where $K=$ conveyance for subelement; $n=$ mannings roughness coefficient for subelement; $A=$ flow area for subelement; $R=$ hydraulic radius for subelement. Subscripts $f$ and $m$ refer to the flood plain and main channel cross sections.

For simplicity, Eq. (1) may be expressed as

$$
z_{1}+y_{1}+\frac{a_{1} Q_{t_{1}}^{2}}{2 g}=z_{2}+y_{2}+\frac{a_{2} Q_{t_{2}}^{2}}{2 g}+h_{e},
$$

where $a=\frac{\propto}{A_{t}^{2}}$.

The formulations of the areas, wetted perimeters and hydraulic radiuses of the subelements of the compound channel are described below.

The floodplain flow area either left or right is computed using the following equation.

$$
A_{f}=\left(B_{f}+\frac{s_{f}(y-Z)}{2}\right)(y-Z)
$$

where $A_{f}=$ flood plain area either left or right, $B_{f}=$ width of flood plain either left or right, $s_{f}=$ side slope of flood bank, $y=$ depth of water, $Z=$ depth of main channel, refer to figure 1 for clear description of notations.

Flow area in main channel is computed as

$$
A_{m}=-s_{m} Z^{2}+2 s_{m} y Z+B_{m} y,
$$

where $A_{m}=$ flow area of main channel, $s_{m}=$ side slope of main channel, $B_{m}=$ bottom width of main channel.

Wetted perimeter of the flood plain either left or right side of the main channel is computed using the following equation.

$$
P_{f}=B_{f}+\sqrt{s_{f}^{2}+1}(y-Z),
$$

where $P_{f}=$ wetted perimeter of the flood plain either left or right side of main channel.

The following equation is used to compute the wetted perimeter of the main channel.

$$
P_{m}=B_{m}+2 Z \sqrt{s_{m}^{2}+1},
$$


where $P_{m}=$ wetted perimeter of the main channel. The hydraulic radius of the floodplain area on either left or right side of the main channel is

$$
R_{f}=\frac{A_{f}}{P_{f}} .
$$

The hydraulic radius of main channel is

$$
R_{m}=\frac{A_{m}}{P_{m}}
$$

where $R_{f}$ and $R_{m}$ are hydraulic radiuses of flood plain and main channel, respectively. The continuity equation between two sections can be written as

$$
Q_{t_{1}}-Q_{t_{2}}=0
$$

where $Q_{t_{1}}$ and $Q_{t_{2}}$ are total discharges at sections 1 and 2, respectively.

\section{Solution algorithm}

Consider a system with $M$ channels, where each channel may have different cross section, manning's $n$ and bed slope. Each channel is subdivided into $N_{i}$ reaches (where $i$ refers to the channel number), with the first section numbered as 1 and last section numbered as $N_{i}+1$. Flow rate $Q_{t}$ and depth $y$ are two unknown variables at each section. The total number of unknowns in the entire channel network are equal to $2 \sum_{i=1}^{i=M}\left(N_{i}+1\right)$. To solve the problem, each section will have two equations (continuity and energy equation), if a channel has $N_{i}$ reaches, then the number of available equations will be $2 N_{i}$, the remaining two equations will be provided as boundary conditions. Known flow discharge at upstream end and known water depth at downstream end are the boundary conditions for a single channel. For the channel network, the continuity and the energy equations in all the reaches, junction equations and boundary conditions comprise the system of equations to solve unknown variables in the entire network. The continuity and energy equations are written for each of the $N_{i}$ reaches of a channel $i$ are as follows.

$$
\begin{gathered}
F_{i, 1}=z_{i, 2}-z_{i, 1}+y_{i, 2}-y_{i, 1}+\frac{1}{2 g}\left(a_{i, 2} Q_{t_{i, 2}}\left|Q_{t_{i, 2}}\right|-a_{i, 1} Q_{t_{i, 1}}\left|Q_{t_{i, 1}}\right|\right)+\left(\frac{\Delta x_{i}}{2}\right)\left(\frac{S_{F_{i, 2}}+S_{F_{i, 1}}}{2}\right)=0 \\
F_{i, 2}=Q_{t_{i, 1}}-Q_{t_{i, 2}}=0 \\
F_{i, 3}=z_{i, 3}-z_{i, 2}+y_{i, 3}-y_{i, 2}+\frac{1}{2 g}\left(a_{i, 3} Q_{t_{i, 3}}\left|Q_{t_{i, 3}}\right|-a_{i, 2} Q_{t_{i, 2}}\left|Q_{t_{i, 2}}\right|\right)+\left(\frac{\Delta x_{i}}{2}\right)\left(\frac{S_{F_{i, 3}}+S_{F_{i, 2}}}{2}\right)=0 \\
(18 \mathrm{~b}) \\
F_{i, 4}=Q_{t_{i, 2}}-Q_{t_{i, 3}}=0 \\
F_{i, 2 N_{i}-1}=z_{i, N_{i}+1}-z_{i, N_{i}}+y_{i, N_{i}+1}-y_{i, N i}+\frac{1}{2 g}\left(a_{i, N_{i}+1} Q_{t_{i, N}+1}\left|Q_{t_{i, N_{i}+1}}\right|\right. \\
\left.-a_{i, 1} Q_{t_{i, N i}}\left|Q_{t_{i, N i}}\right|\right)+\left(\frac{\Delta x_{i}}{2}\right)\left(\frac{S_{F_{i, N_{i}+1}}+S_{F_{i, 1}}}{2}\right)=0
\end{gathered}
$$




$$
F_{i, 2 N_{i}}=Q_{t_{i, N_{i}}}-Q_{t_{i, N_{i}+1}}=0 .
$$

In $F_{i, j}$, where subscripts $i$ and $j$ denote channel number and equation number, respectively for the first reach. Similarly, a set of equations is formulated for all the channels of the network, thus totaling $2 \sum_{i=1}^{i=M} N_{i}$ number of equations. Remaining $2 M$ equations are supplemented by the boundary conditions and junction equations. Junction conditions and boundary equations presented by Schulte \& Chaudhry (1987) are given below.

\subsection{Junction equations}

The available equations at any channel junction are equal to the number of channels joining at that junction. Either, two upstream channels joining with a downstream channel or one upstream channel joining with two downstream channels give three equations, which consist of two energy equations and one continuity equation. The energy losses and the differences in the velocity heads are neglected at the junction. The continuity equation and the two energy equations at junction $(J 1)$ of one upstream channel and two downstream channels shown in figure 3 a can be written as follows.

Continuity equation for the junction

$$
F_{J 1,1}=Q_{t_{i, N_{i}+1}}-Q_{t_{i+1,1}}-Q_{t_{i+2,1}}=0 .
$$

First energy equation for the junction

$$
F_{J 1,2}=y_{i, N_{i}+1}-y_{i+1,1}=0 .
$$

Second energy equation for the junction

$$
F_{J 1,3}=y_{i, N_{i}+1}-y_{i+2,1}=0 .
$$

The following three equations are available at the junction $(J 2)$ of two upstream channels and one downstream channel as shown figure $3 \mathrm{~b}$.

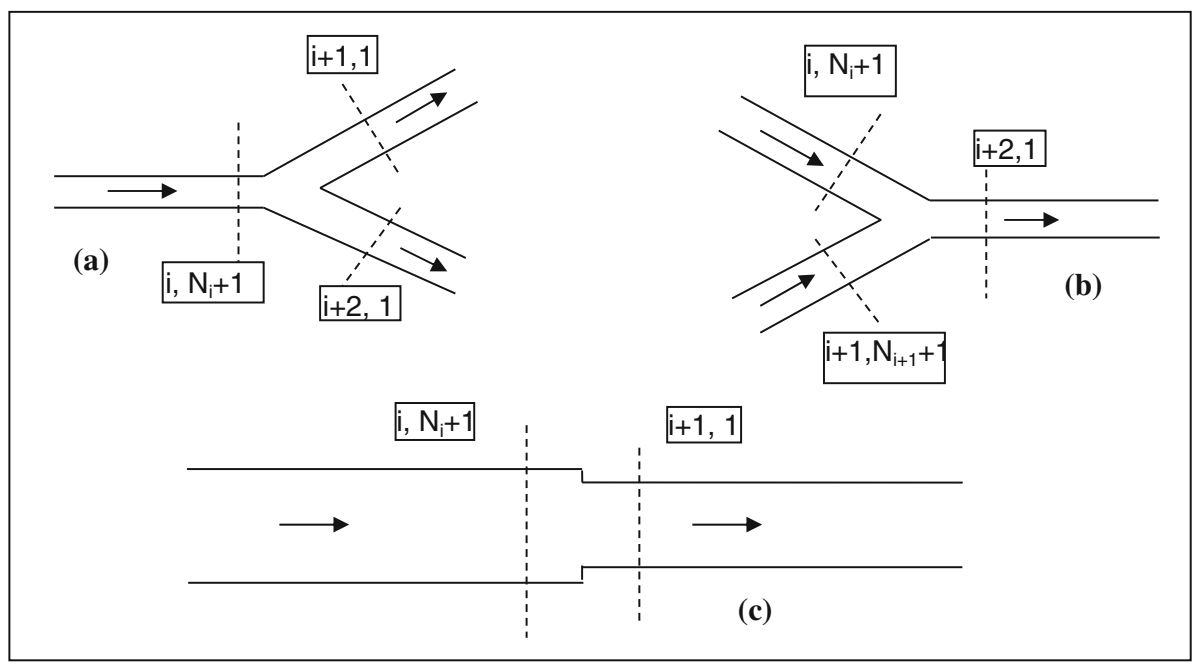

Figure 3. Channel junctions: (a) two $\mathrm{d} / \mathrm{s}$ channels and one u/s channel, (b) two $\mathrm{u} / \mathrm{s}$ channels and one d/s channel and (c) two channels in series. 
Continuity equation for the junction

$$
F_{J 2,1}=Q_{t_{i, N_{i}+1}}-Q_{t_{i+1, N_{i+1}+1}}-Q_{t_{i+2,1}}=0 .
$$

First energy equation for the junction

$$
F_{J 2,2}=y_{i, N_{i}+1}-y_{i+1, N_{i+1}+1}=0 .
$$

Second energy equation for the junction

$$
F_{J 2,3}=y_{i, N_{i}+1}-y_{i+1,1}=0 .
$$

Similarly, the following two equations are available at the junction (J3) of two series channels where different sections join as shown in figure $3 \mathrm{c}$.

$$
\begin{gathered}
F_{J 3,1}=Q_{t_{i, N_{i}+1}}-Q_{t_{i+1,1}}=0 . \\
F_{J 3,2}=y_{i, N_{i}+1}-y_{i+1,1}=0 .
\end{gathered}
$$

\subsection{Boundary conditions}

Only subcritical flow is considered here. For subcritical flow, the end conditions consist of a specified flow depth $y_{d}$ at all the pendant nodes and a specified discharge $Q_{t_{u}}$ at the inflow nodes of the network as shown in figure 4 .

The upstream and downstream boundary conditions of one upstream channel and two downstream channels (figure 4a) may be written as below.

Upstream boundary condition

$$
F_{B C, 1}=Q_{t_{i, u b c}}-Q_{t_{i, 1}}=0 .
$$

First downstream boundary condition

$$
F_{B C, 2}=y_{i+1, d b c}-y_{i+1, N_{i+1}+1}=0 .
$$

Second downstream boundary condition

$$
F_{B C, 3}=y_{i+2, d b c}-y_{i+2, N_{i+2}+1}=0 .
$$

Similarly, the upstream and downstream boundary conditions of two upstream channels and one downstream channel (figure 4b) may be written as following.

Upstream boundary conditions

$$
\begin{gathered}
F_{B C, 1}=Q_{t_{i, u b c}}-Q_{t_{i, 1}}=0, \\
F_{B C, 2}=Q_{t_{i+1, u b c}}-Q_{t_{i+1,1}}=0 .
\end{gathered}
$$

Downstream boundary condition

$$
F_{B C, 3}=y_{i+2, d b c}-y_{i+2, N_{i+2}+1}=0 .
$$




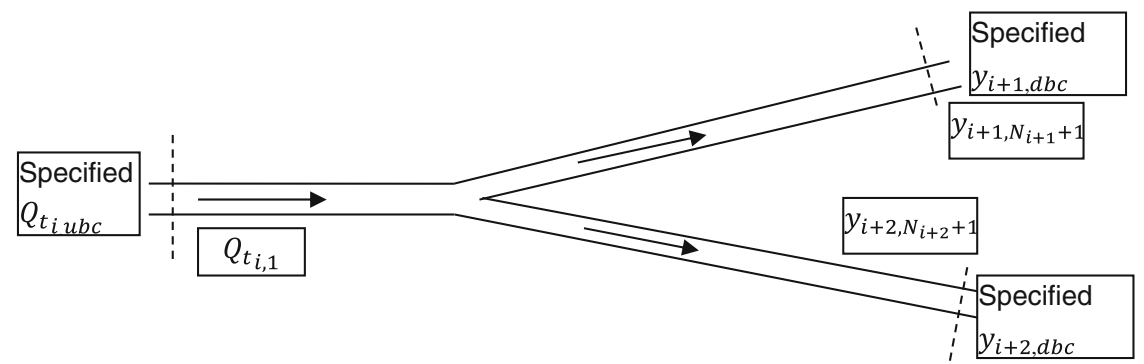

(a) One entry channel and two downstream channels

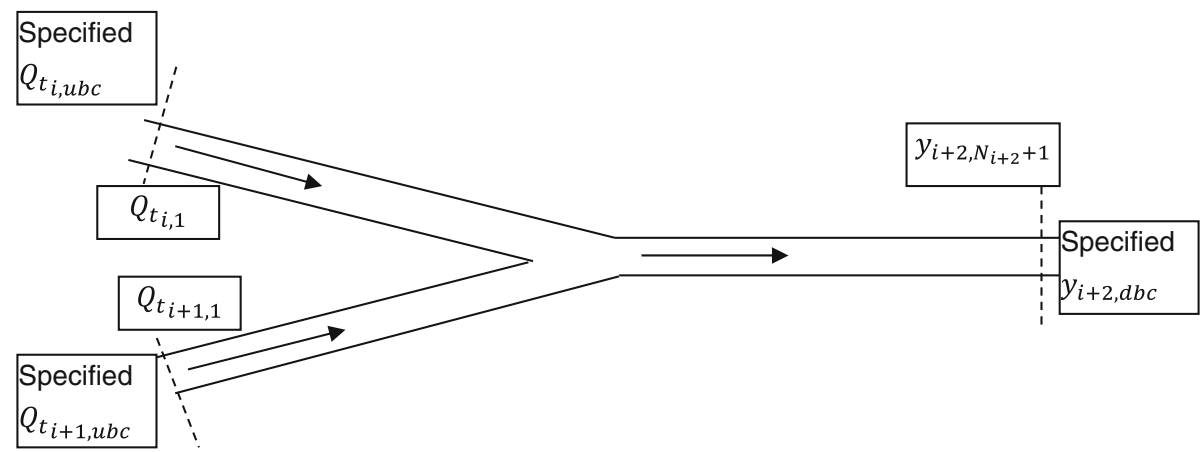

(b) Two entry channels and one downstream channel.

Figure 4. Specification of boundary conditions.

The equations described above are solved by using the Newton-Raphson method. Partial derivatives of flow variables for all the equations are required for this method. The derivatives are formed as a Jacobian matrix for an iterative solution. The following derivatives for different equations (A1-A3) are presented in Appendix I.

\section{Solution procedure}

A matrix of system of equations is formed by grouping of the continuity and the energy equations in reaches, the junction equations and the boundary conditions. The solution procedure starts with arbitrary initial estimates of $y_{i, j}^{(0)}$ and $Q_{t_{i, j}}^{(0)}$ at each and every section of the network. Reasonable initial values may be assigned by setting them equal to boundary conditions or by using the experience. The Newton-Raphson method is an iterative procedure and corrections in the flow rates and depths are obtained between iterations. Improved values of the flow variables at subsequent intervals are obtained by adding corrections to the previous values by applying a relaxation factor.

$$
\begin{gathered}
Q_{t_{i, j}}^{(\text {new })}=Q_{t_{i, j}}^{\text {(previous })}+r \Delta Q_{t_{i, j}} \\
y_{i, j}^{\text {(new })}=y_{i, j}^{(\text {previous })}+r \Delta y_{t_{i, j}},
\end{gathered}
$$

where $r$ is a relaxation factor. Patankar (1980) suggested that $r<1$ improves the convergence of simultaneous solution. For simple networks, $r=1$ gives the faster convergence. 


\section{Generalized application}

This general method is applicable to compound channel networks, trapezoidal channel networks as well as mixed channel networks (where some channels are with compound cross sections and remaining channels are with trapezoidal cross section). If the water level goes below the flood plain level for any channel i.e., $y \leq Z$ then $Z=y$ is assigned and variables $A_{f}, B_{f}, R_{f}, P_{f}$ as well as their derivatives $d a / d A_{f}, d A_{f} / d y, d R_{f} / d y, d a / d R_{f}, d S_{F} / d A_{f}$, and $d S_{F} / d R_{f}$ for that channel are equal to zero. The derivative of hydraulic radius of main channel with respect to depth is updated with the following equation.

$$
\frac{d R_{m}}{d y}=\frac{B_{m}+2 Z s_{m}}{P_{m}}-\frac{2 R_{m} \sqrt{s_{f}^{2}+1}}{P_{m}} .
$$

\section{Froude number calculation}

Froude number in a compound channel is computed using the following equation (Chaudhry \& Bhallamudi 1988). This criterion may be used to determine the occurrence of critical flow in a channel.

$$
F_{r}=\frac{\beta V}{\sqrt{\frac{g A_{t}}{B}+V^{2}\left(\beta^{2}-\beta+\frac{A_{t} \beta^{\prime}}{B}\right)}},
$$

where $F_{r}=$ Froude number; $V=$ average velocity; $B=$ top width of flow area; $A_{t}=$ total flow area; $\beta=$ momentum coefficient, $\beta^{\prime}=d \beta / d y$.

$$
\beta=\frac{A_{t}}{K_{t}^{2}}\left[\frac{2 K_{f}^{2}}{A_{f}}+\frac{K_{m}^{2}}{A_{m}}\right],
$$

where $K=$ conveyance for subelement; $A=$ flow area for subelement; Subscripts $f, m$ and $t$ refer to the flood plain, main channel and total channel cross sections.

\section{Critical depth computation}

In this section, a methodology is presented to compute the critical depths for a given discharge in a compound channel. Chaudhry \& Bhallamudi (1988) presented an algorithm to compute critical depths one by one in an efficient way. However, Chaudhry \& Bhallamudi (1988) method to compute the critical depths is difficult to implement, cumbersome and convergence is specific to initial value. HEC-RAS (Brunner 2010) uses 'parabolic' and 'secant' methods to calculate critical depths. The present method outlined below is non-iterative and robust compared to the available methods.

(i) Compute the Froude number using the Eq. (36) for flow depths beginning from $0.5 \mathrm{Z}$ to maximum of $1.5 \mathrm{Z}$ with a depth increment of $0.01 \mathrm{Z}$.

(ii) Store computed Froude numbers and corresponding flow depths in arrays with index starting from 1. Froude numbers are stored in array $F_{r}$ and Depths are stored in array $Y$. 
(iii) Subtract 1.0 from stored Froude numbers and save them in another array with same indexes. Suppose name the new array as $F_{r m_{1}}$.

(iv) Determine the indexes corresponding to sign change of elements of array $F_{r m_{1}}$

(v) Critical depths are depths in $Y$ corresponding to indexes determined in step 4.

\section{Model application}

The developed model is applied to two different types of channel networks. In the first case, a tree network of channels with compound channel cross sections is considered. In the second case, the model is applied to a looped channel network. The detailed description of the input channel characteristics, boundary conditions and model output for both networks are described in the following paragraphs.

\subsection{Tree-type channel network}

A tree-type channel network as shown in figure 5 is modelled. The channel numbers and node numbers are shown in figure 5. There are 41 channels and 42 nodes in the network. The channel characteristics are given in table 1 . The flow in the entire channel system is subcritical. The flow and depth boundary conditions are given in table 2 . The upstream discharge is $Q_{u}=250$ $\mathrm{m}^{3} / \mathrm{s}$. The following notation is used in table 1 . Channel number is represented by $i, D / S$ is downstream, $B_{f}$ is flood plain width, $s_{f}$ is side slope of bank of flood plain, $s_{m}$ is side slope of

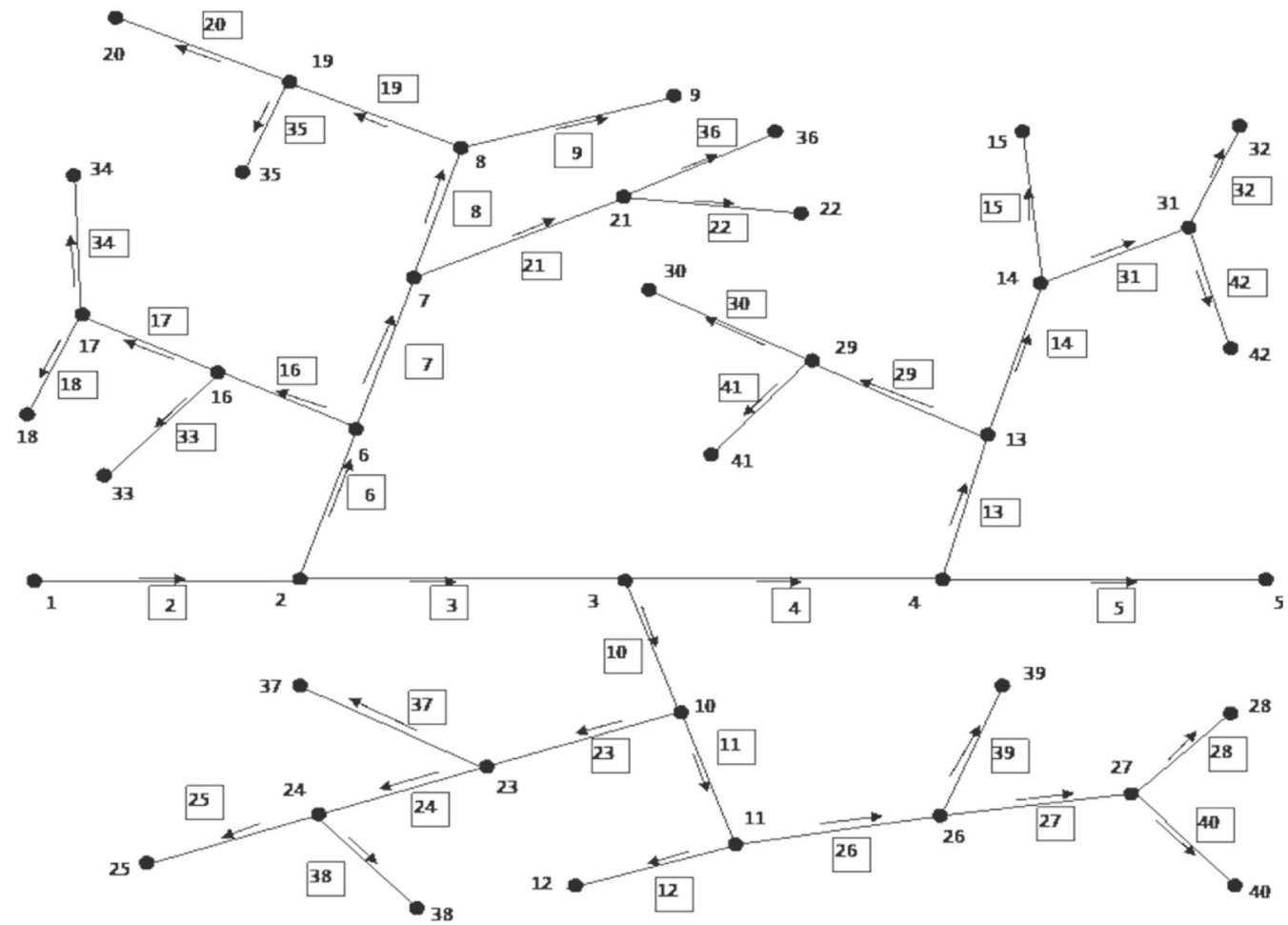

Figure 5. Tree channel network. 
Table 1. Channel characteristics of the tree-type compound channel network.

\begin{tabular}{|c|c|c|c|c|c|c|c|c|c|c|c|c|c|}
\hline $\mathrm{i}$ & U/S node & D/S node & $\mathrm{B}_{\mathrm{f}}(\mathrm{m})$ & $\mathrm{Z}(\mathrm{m})$ & $\mathrm{s}_{\mathrm{f}}$ & $\mathrm{B}_{\mathrm{m}}(\mathrm{m})$ & $s_{\mathrm{m}}$ & $\mathrm{L}(\mathrm{m})$ & $\mathrm{S}_{\mathrm{o}}$ & $\mathrm{n}_{\mathrm{f}}$ & $\mathrm{n}_{\mathrm{m}}$ & $\mathrm{Q}_{\mathrm{i}}$ & $\mathrm{y}_{\mathrm{i}}$ \\
\hline 2 & 1 & 2 & 20 & 2.6 & 2 & 25 & 1.5 & 2500 & 0.00013 & 0.015 & 0.015 & 40.0 & 3.0 \\
\hline 3 & 2 & 3 & 14 & 2.1 & 1 & 14 & 1.5 & 2000 & 0.00015 & 0.016 & 0.016 & 40.0 & 2.8 \\
\hline 4 & 3 & 4 & 13.5 & 1.8 & 2 & 13.5 & 1 & 1700 & 0.00016 & 0.018 & 0.017 & 40.0 & 2.6 \\
\hline 5 & 4 & 5 & 2.9 & 1.5 & 2 & 2.9 & 1.5 & 1500 & 0.00017 & 0.019 & 0.018 & 40.0 & 2.5 \\
\hline 6 & 2 & 6 & 12 & 2 & 2 & 12 & 1 & 1500 & 0.00020 & 0.020 & 0.020 & 20.0 & 1.8 \\
\hline 7 & 6 & 7 & 7.5 & 1.9 & 2 & 7.5 & 1 & 1400 & 0.00021 & 0.020 & 0.020 & 20.0 & 1.7 \\
\hline 8 & 7 & 8 & 3 & 1.85 & 1 & 3 & 0 & 1200 & 0.00022 & 0.020 & 0.020 & 5.0 & 1.5 \\
\hline 9 & 8 & 9 & 3 & 2 & 2 & 3 & 2 & 1000 & 0.00024 & 0.023 & 0.022 & 5.0 & 1.5 \\
\hline 10 & 3 & 10 & 3.75 & 2.1 & 2 & 3.75 & 0.5 & 1400 & 0.00025 & 0.024 & 0.022 & 5.0 & 1.7 \\
\hline 11 & 10 & 11 & 3 & 1.6 & 2 & 3 & 0.5 & 1200 & 0.00022 & 0.020 & 0.022 & 5.0 & 1.3 \\
\hline 12 & 11 & 12 & 1.75 & 1.8 & 2 & 1.75 & 2 & 1000 & 0.00024 & 0.023 & 0.022 & 5.0 & 1.0 \\
\hline 13 & 4 & 13 & 5 & 1.8 & 2 & 5 & 2 & 1300 & 0.00022 & 0.022 & 0.022 & 5.0 & 1.5 \\
\hline 14 & 13 & 14 & 3 & 1.8 & 1 & 3 & 1 & 1200 & 0.00025 & 0.025 & 0.022 & 5.0 & 1.4 \\
\hline 15 & 14 & 15 & 0.5 & 1.6 & 2 & 0.5 & 4 & 1000 & 0.00022 & 0.024 & 0.022 & 5.0 & 1.0 \\
\hline 16 & 6 & 16 & 1 . & 1.6 & 2 & 1.5 & 4 & 1000 & 0.00024 & 0.022 & 0.022 & 5.0 & 1.7 \\
\hline 17 & 16 & 17 & 1.75 & 1.9 & 2 & 1.75 & 0.5 & 1000 & 0.00025 & 0.023 & 0.022 & 5.0 & 1.6 \\
\hline 18 & 17 & 18 & 1.5 & 1.6 & 2 & 1.5 & 1.5 & 1000 & 0.00024 & 0.022 & 0.022 & 5.0 & 1.4 \\
\hline 19 & 8 & 19 & 1.5 & 2 & 1 & 1.5 & 2 & 1000 & 0.00024 & 0.026 & 0.022 & 5.0 & 1.5 \\
\hline 20 & 19 & 20 & 0.75 & 1.6 & 2 & 0.75 & 0.9 & 900 & 0.00025 & 0.025 & 0.022 & 5.0 & 1.7 \\
\hline 21 & 7 & 21 & 1.5 & 1.6 & 2 & 1.5 & 2 & 1100 & 0.00024 & 0.024 & 0.022 & 5.0 & 1.5 \\
\hline 22 & 21 & 22 & 1 & 1.6 & 2 & 1 & 1 & 1000 & 0.00025 & 0.023 & 0.022 & 1.0 & 1.6 \\
\hline 23 & 10 & 23 & 1.75 & 1.7 & 1 & 1.75 & 1 & 1200 & 0.00024 & 0.022 & 0.022 & 1.0 & 1.3 \\
\hline 24 & 23 & 24 & 1.5 & 1.5 & 2 & 1.5 & 1 & 1100 & 0.00024 & 0.024 & 0.022 & 1.0 & 1.2 \\
\hline 25 & 24 & 25 & 1.5 & 1.6 & 2 & 0.75 & 1 & 1000 & 0.00025 & 0.025 & 0.025 & 1.0 & 1.3 \\
\hline 26 & 11 & 26 & 3 & 1.6 & 2 & 1.5 & 2 & 1200 & 0.00024 & 0.020 & 0.020 & 1.0 & 1.0 \\
\hline 27 & 26 & 27 & 2.5 & 1.6 & 2 & 1.25 & 2 & 1000 & 0.00024 & 0.022 & 0.022 & 1.0 & 1.1 \\
\hline 28 & 27 & 28 & 2 & 1.6 & 2 & 0.75 & 2.5 & 900 & 0.00024 & 0.025 & 0.022 & 1.0 & 1.2 \\
\hline 29 & 13 & 29 & 4 & 1.8 & 1 & 2 & 1.5 & 900 & 0.00025 & 0.025 & 0.022 & 1.0 & 1.4 \\
\hline 30 & 29 & 30 & 2.5 & 1.6 & 2 & 1.25 & 1 & 800 & 0.00025 & 0.025 & 0.022 & 1.0 & 1.2 \\
\hline 31 & 14 & 31 & 2 & 1.5 & 2 & 1 & 2 & 800 & 0.00024 & 0.025 & 0.022 & 1.0 & 0.8 \\
\hline 32 & 31 & 32 & 1 & 1.3 & 2 & 0.5 & 2.5 & 700 & 0.00050 & 0.022 & 0.022 & 1.0 & 1.0 \\
\hline 33 & 16 & 33 & 1.5 & 1.6 & 2 & 0.75 & 1 & 700 & 0.00050 & 0.030 & 0.030 & 1.0 & 1.5 \\
\hline 34 & 17 & 34 & 1 & 2 & 2 & 0.5 & 1 & 700 & 0.00050 & 0.030 & 0.030 & 1.0 & 1.4 \\
\hline 35 & 19 & 35 & 1 & 1.6 & 1 & 0.5 & 1 & 700 & 0.00050 & 0.031 & 0.030 & 1.0 & 1.7 \\
\hline 36 & 21 & 36 & 2 & 2 & 2 & 1 & 1 & 700 & 0.00050 & 0.032 & 0.030 & 1.0 & 1.6 \\
\hline 37 & 23 & 37 & 1 & 1.4 & 2 & 0.5 & 1 & 700 & 0.00050 & 0.035 & 0.030 & 0.5 & 1.3 \\
\hline 38 & 24 & 38 & 1 & 1.5 & 2 & 0.5 & 1 & 700 & 0.00050 & 0.035 & 0.030 & 0.5 & 1.3 \\
\hline 39 & 26 & 39 & 1 & 1 & 1 & 0.5 & 1 & 700 & 0.00050 & 0.030 & 0.030 & 0.5 & 1.1 \\
\hline 40 & 27 & 40 & 1 & 1.4 & 2 & 0.5 & 1 & 700 & 0.00050 & 0.032 & 0.030 & 0.5 & 1.2 \\
\hline 41 & 29 & 41 & 2 & 1.5 & 2 & 1 & 1 & 700 & 0.00050 & 0.031 & 0.030 & 0.5 & 1.2 \\
\hline 42 & 31 & 42 & 1 & 1.2 & 2 & 0.5 & 1 & 700 & 0.00050 & 0.024 & 0.030 & 0.5 & 1.0 \\
\hline
\end{tabular}

main channel, $n_{f}$ is roughness of the flood plain, $n_{m}$ is roughness of main channel. Each channel is discretized into 20 reaches. The iterative procedure is started by assuming the initial discharges $Q_{i}$ and initial depths $y_{i}$ at all the sections in each channel as presented in the table 1 . A tolerance of 0.001 for $y_{i j}$ and $Q_{i j}$ is specified for convergence. The solution converges after 55 iterations. The computed discharges and water depths at different cross sections are shown in table 3 . The 
Table 2. Boundary conditions of the tree-channel network.

\begin{tabular}{lcc}
\hline & Flow boundary conditions & \\
U/S node number & & Flow rate $\left(\mathrm{m}^{3} / \mathrm{s}\right)$ \\
1 & Depth boundary conditions & 250.00 \\
& & \\
D/S node number & Water depth $(\mathrm{m})$ \\
5 & 0.91 \\
9 & 1.66 \\
12 & 0.98 \\
15 & 0.91 \\
18 & 1.60 \\
20 & 1.88 \\
22 & 1.67 \\
25 & 1.36 \\
28 & 1.48 \\
30 & 1.17 \\
32 & 1.07 \\
33 & 1.48 \\
34 & 1.71 \\
35 & 2.01 \\
36 & 1.78 \\
37 & 1.22 \\
38 & 1.47 \\
39 & 1.37 \\
40 & 1.61 \\
41 & 1.33 \\
42 & 1.25 \\
\hline
\end{tabular}

computed flow variables are validated with the HEC-RAS 4.1 software for individual channels. Flow rate and downstream depth are known for all the channels in the network (which are already computed using the proposed method) and upstream flow depth and critical depth are computed independently for each and every channel in the network using HEC-RAS by inputting known downstream flow depth and flow rates. HEC-RAS computed upstream flow depth is compared with the upstream flow depth computed using the proposed method. The maximum difference between flow depths computed by using HEC-RAS and the proposed method is less than 0.01 $\mathrm{m}$. The HEC-RAS computed upstream flow depths and critical depths are given in brackets in table 3. The maximum deviation in computed depth at a junction due to neglecting difference in velocity heads and energy losses at the junction is found to be $0.04 \mathrm{~m}$, which is evaluated by dividing the tree channel network into many three channel networks (one incoming and two outgoing channels) and flow variables are computed using HEC-RAS 4.1. HEC-RAS computed water depths are compared with solution of the proposed method to determine the maximum error in depth computation caused by neglecting velocity head differences and energy losses at the junction. However, HEC-RAS 4.1 is giving different flow depths in channels meeting at the junction (one incoming channel and two outgoing channels) which may not be correct in subcritical flows.

\subsection{Looped channel network}

In the second case, a looped channel network as shown in figure 6 is simulated. There are ten channels and eight nodes in this looped network. The main channel and the floodplain have side 
Table 3. Computed water depths and discharges in the tree-channel network.

\begin{tabular}{|c|c|c|c|c|}
\hline $\mathrm{i}$ & Discharge $\left(\mathrm{m}^{3} / \mathrm{s}\right)$ & U/S depth (m) & $\mathrm{D} / \mathrm{S}$ depth $(\mathrm{m})$ & Critical depths (m) \\
\hline 2 & 250.00 & $3.65(3.66)$ & 3.42 & $2.05(2.07)$ \\
\hline 3 & 137.89 & $3.42(3.42)$ & 3.38 & $1.97,2.12,2.20(1.98)$ \\
\hline 4 & 100.68 & $3.38(3.39)$ & 3.50 & $1.69,1.80,1.92(1.70)$ \\
\hline 5 & 24.03 & $3.50(3.49)$ & 3.69 & $1.47,1.5,1.56(1.56)$ \\
\hline 6 & 112.11 & $3.42(3.42)$ & 3.35 & $1.94,2.00,2.20(2.23)$ \\
\hline 7 & 68.02 & $3.35(3.35)$ & 3.36 & $1.84,1.90,2.07(2.10)$ \\
\hline 8 & 26.28 & $3.36(3.37)$ & 2.73 & $2.24(2.28)$ \\
\hline 9 & 16.56 & $2.11(2.12)$ & 1.66 & $1.12(1.13)$ \\
\hline 10 & 37.21 & $3.38(3.39)$ & 2.66 & $1.95,2.14,2.18(1.96)$ \\
\hline 11 & 20.87 & $2.66(2.67)$ & 1.93 & $1.55,1.6,1.76(1.54)$ \\
\hline 12 & 10.39 & $1.93(1.93)$ & 1.45 & $1.04(1.05)$ \\
\hline 13 & 76.65 & $3.50(3.50)$ & 3.35 & $2.20(2.22)$ \\
\hline 14 & 43.21 & $3.35(3.36)$ & 2.68 & $2.20(2.23)$ \\
\hline 15 & 18.16 & $2.68(2.67)$ & 2.81 & $1.26(1.27)$ \\
\hline 16 & 44.08 & $3.35(3.35)$ & 3.47 & $1.73(1.73)$ \\
\hline 17 & 26.56 & $3.47(3.48)$ & 2.51 & $2.36(2.39)$ \\
\hline 18 & 18.57 & $2.51(2.53)$ & 1.60 & $1.55(1.56,1.61)$ \\
\hline 19 & 9.72 & $2.11(2.11)$ & 2.09 & $1.04(1.05)$ \\
\hline 20 & 5.12 & $2.09(2.09)$ & 1.88 & $1.10(1.11)$ \\
\hline 21 & 41.74 & $3.36(3.37)$ & 3.19 & $2.08(2.10)$ \\
\hline 22 & 20.95 & $3.19(3.19)$ & 3.0 & $2.02(2.04)$ \\
\hline 23 & 16.33 & $2.66(2.66)$ & 2.24 & $1.53(1.54)$ \\
\hline 24 & 9.68 & $2.24(2.25)$ & 2.02 & $1.23(1.23)$ \\
\hline 25 & 4.94 & $2.02(2.02)$ & 1.36 & $1.06(1.06)$ \\
\hline 26 & 10.49 & $1.93(1.93)$ & 1.74 & 1.09 (1.09) \\
\hline 27 & 6.61 & $1.74(1.74)$ & 1.55 & $0.90(0.91)$ \\
\hline 28 & 4.75 & $1.55(1.55)$ & 1.48 & $0.80(0.80)$ \\
\hline 29 & 33.45 & $3.35(3.35)$ & 3.39 & $2.03(2.06)$ \\
\hline 30 & 16.64 & $3.39(3.38)$ & 3.51 & $1.81(1.83)$ \\
\hline 31 & 25.05 & $2.68(2.68)$ & 2.42 & $1.77(1.77)$ \\
\hline 32 & 16.36 & $2.42(2.41)$ & 2.60 & $1.46(1.46)$ \\
\hline 33 & 17.52 & $3.47(3.46)$ & 3.65 & $1.95(1.98)$ \\
\hline 34 & 7.99 & $2.51(2.51)$ & 1.71 & $1.44(1.44)$ \\
\hline 35 & 4.60 & $2.09(2.09)$ & 2.01 & $1.10(1.12)$ \\
\hline 36 & 20.79 & $3.19(3.20)$ & 2.94 & $2.12(2.13)$ \\
\hline 37 & 6.65 & $2.24(2.25)$ & 2.02 & $1.32(1.32)$ \\
\hline 38 & 4.74 & $2.02(2.02)$ & 1.47 & $1.13(1.13)$ \\
\hline 39 & 3.87 & $1.74(1.74)$ & 1.37 & $1.08(1.09)$ \\
\hline 40 & 1.87 & $1.55(1.55)$ & 1.61 & $0.71(0.72)$ \\
\hline 41 & 16.80 & 3.39 (3.39) & 3.60 & $1.83(1.86)$ \\
\hline 42 & 8.69 & $2.42(2.42)$ & 2.49 & $1.49(1.51)$ \\
\hline
\end{tabular}

slopes of $2 \mathrm{H}: 1 \mathrm{~V}$. Flow in all the channels is subcritical. The boundary conditions at the downstream node $y_{d}=6.0 \mathrm{~m}$ and inflow discharge $Q_{u}=125.0 \mathrm{~m}^{3} / \mathrm{s}$. The remaining channel characteristics are presented in table 4. A constant bed slope of 0.0001 is specified for all the channels. Each channel is discretized into 20 reaches for computations. 


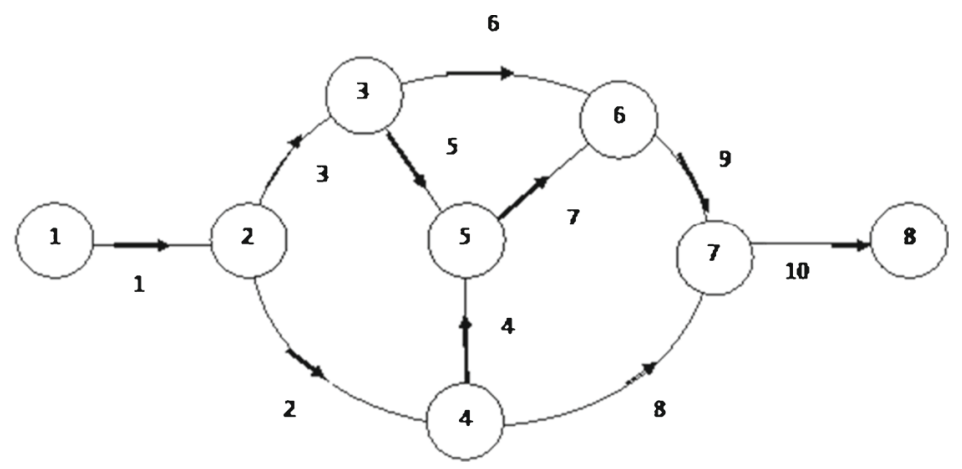

Figure 6. Looped channel network.

Table 4. Channel characteristics of looped channel network.

\begin{tabular}{lllllllllll}
\hline $\mathrm{i}$ & $\mathrm{U} / \mathrm{S}$ node & $\mathrm{D} / \mathrm{S}$ node & $\mathrm{B}_{\mathrm{f}}(\mathrm{m})$ & $\mathrm{Z}(\mathrm{m})$ & $\mathrm{s}_{f}$ & $\mathrm{~B}_{\mathrm{m}}$ & $\mathrm{s}_{\mathrm{m}}$ & $\mathrm{L}(\mathrm{m})$ & $\mathrm{n}_{\mathrm{f}}$ & $\mathrm{n}_{\mathrm{m}}$ \\
\hline 1 & 1 & 2 & 10 & 2.5 & 2 & 16 & 2 & 10000 & 0.025 & 0.02 \\
2 & 2 & 3 & 6 & 2.5 & 2 & 7 & 2 & 5000 & 0.024 & 0.02 \\
3 & 2 & 4 & 6 & 2 & 2 & 5 & 2 & 5000 & 0.023 & 0.02 \\
4 & 3 & 5 & 5 & 2.5 & 1 & 1.75 & 1.5 & 5000 & 0.026 & 0.02 \\
5 & 4 & 5 & 5 & 2 & 1 & 3.25 & 1.5 & 5000 & 0.030 & 0.02 \\
6 & 4 & 6 & 6 & 2 & 1 & 4.5 & 1.5 & 10000 & 0.025 & 0.02 \\
7 & 5 & 6 & 6 & 2.5 & 1 & 6 & 2 & 5000 & 0.028 & 0.02 \\
8 & 3 & 7 & 7 & 2 & 2 & 7 & 2 & 15000 & 0.020 & 0.018 \\
9 & 6 & 7 & 7 & 2.5 & 2 & 9 & 2 & 5000 & 0.025 & 0.02 \\
10 & 7 & 8 & 10 & 2 & 2 & 15 & 2 & 10000 & 0.026 & 0.02 \\
\hline
\end{tabular}

The iterative procedure is started by assuming the flow depth equal to $6.0 \mathrm{~m}$ and discharge equal to $75.0 \mathrm{~m}^{3} / \mathrm{s}$. A tolerance of 0.001 for $y_{i j}$ and $Q_{i j}$ is specified for convergence. The solution was converged after 10 iterations. The computed discharges, critical depths and water depths at different cross sections are shown in table 5.

\section{Critical depths in compound channel networks}

Computation of water surface profile in a compound channel is more difficult than trapezoidal channel because there may be more than one critical depth. In this section, examples of such type of channels are presented. Computed water surface profiles for the tree channel network as shown in figure 5 are presented in table 3 . In addition, water surface profiles are also computed for the looped channel network as shown in figure 6 and are presented in table 5. Computed critical depths of tree channel network are presented in column 4 of table 3. Multiple critical depths are observed for channels 3, 4, 5, 6, 7, 10 and 11. For channel 4, critical depths $Y_{c 1}, Y_{c 2}$ and $Y_{c 3}$ are $1.69,1.80$ and $1.92 \mathrm{~m}$, respectively and the upstream water surface elevation is $3.38 \mathrm{~m}$ for the given discharge. A typical variation of Froude number with depth for a compound channel is presented in figure 7a. Hydraulic gradient and critical depth lines are as shown in figure $7 \mathrm{~b}$. Chaudhry \& Bhallamudi (1988) developed non-dimensional plots to design symmetrical 
Table 5. Computed water depths, critical depths and discharges in the looped channel network.

\begin{tabular}{|c|c|c|c|c|c|c|c|}
\hline & Section & $\begin{array}{l}\text { Distance } \\
\text { (m) }\end{array}$ & $\begin{array}{l}\text { Depth } \\
\text { (m) }\end{array}$ & & Section & $\begin{array}{l}\text { Distance } \\
(\mathrm{m})\end{array}$ & $\begin{array}{l}\text { Depth } \\
\text { (m) }\end{array}$ \\
\hline Channel 1 & 1 & 0 & 4.06 & Channel 6 & 1 & 0 & 4.10 \\
\hline \multirow[t]{4}{*}{$\mathrm{Q}=125.00 \mathrm{~m}^{3} / \mathrm{s}$} & 2 & 2000 & 4.05 & $\mathrm{Q}=32.97 \mathrm{~m}^{3} / \mathrm{s}$ & 2 & 2000 & 4.24 \\
\hline & 3 & 4000 & 4.04 & & 3 & 4000 & 4.39 \\
\hline & 4 & 6000 & 4.02 & & 4 & 6000 & 4.55 \\
\hline & 5 & 8000 & 4.01 & & 5 & 8000 & 4.71 \\
\hline Critical depth $=1.70 \mathrm{~m}$ & 6 & 10000 & 3.98 & Critical depth $=1.48 \mathrm{~m}$ & 6 & 10000 & 4.88 \\
\hline Channel 2 & 1 & 0 & 3.98 & Channel 7 & 1 & 0 & 4.47 \\
\hline \multirow[t]{4}{*}{$\mathrm{Q}=66.07 \mathrm{~m}^{3} / \mathrm{s}$} & 2 & 1000 & 3.99 & $\mathrm{Q}=39.45 \mathrm{~m}^{3} / \mathrm{s}$ & 2 & 1000 & 4.55 \\
\hline & 3 & 2000 & 4.00 & & 3 & 2000 & 4.63 \\
\hline & 4 & 3000 & 4.01 & & 4 & 3000 & 4.71 \\
\hline & 5 & 4000 & 4.02 & & 5 & 4000 & 4.79 \\
\hline Critical depth $=1.75 \mathrm{~m}$ & 6 & 5000 & 4.03 & Critical depth $=1.38 \mathrm{~m}$ & 6 & 5000 & 4.88 \\
\hline Channel 3 & 1 & 0 & 3.98 & Channel 8 & 1 & 0 & 4.03 \\
\hline \multirow[t]{4}{*}{$\mathrm{Q}=58.93 \mathrm{~m}^{3} / \mathrm{s}$} & 2 & 1000 & 4.00 & $\mathrm{Q}=52.58 \mathrm{~m}^{3} / \mathrm{s}$ & 2 & 3000 & 4.24 \\
\hline & 3 & 2000 & 4.03 & & 3 & 6000 & 4.47 \\
\hline & 4 & 3000 & 4.05 & & 4 & 9000 & 4.72 \\
\hline & 5 & 4000 & 4.08 & & 5 & 12000 & 4.98 \\
\hline Critical depth $=1.86 \mathrm{~m}$ & 6 & 5000 & 4.10 & Critical depth $=1.52 \mathrm{~m}$ & 6 & 15000 & 5.24 \\
\hline Channel 4 & 1 & 0 & 4.03 & Channel 9 & 1 & 0 & 4.88 \\
\hline \multirow[t]{4}{*}{$\mathrm{Q}=13.48 \mathrm{~m}^{3} / \mathrm{s}$} & 2 & 1000 & 4.12 & $\mathrm{Q}=72.42 \mathrm{~m}^{3} / \mathrm{s}$ & 2 & 1000 & 4.95 \\
\hline & 3 & 2000 & 4.20 & & 3 & 2000 & 5.02 \\
\hline & 4 & 3000 & 4.29 & & 4 & 3000 & 5.09 \\
\hline & 5 & 4000 & 4.38 & & 5 & 4000 & 5.17 \\
\hline Critical depth $=1.28 \mathrm{~m}$ & 6 & 5000 & 4.47 & Critical depth $=1.63 \mathrm{~m}$ & 6 & 5000 & 5.24 \\
\hline Channel 5 & 1 & 0 & 4.10 & Channel 10 & 1 & 0 & 5.24 \\
\hline \multirow[t]{4}{*}{$\mathrm{Q}=25.97 \mathrm{~m}^{3} / \mathrm{s}$} & 2 & 1000 & 4.17 & $\mathrm{Q}=125.00 \mathrm{~m}^{3} / \mathrm{s}$ & 2 & 2000 & 5.38 \\
\hline & 3 & 2000 & 4.25 & & 3 & 4000 & 5.53 \\
\hline & 4 & 3000 & 4.32 & & 4 & 6000 & 5.68 \\
\hline & 5 & 4000 & 4.39 & & 5 & 8000 & 5.84 \\
\hline Critical depth $=1.46 \mathrm{~m}$ & 6 & 5000 & 4.47 & Critical depth $=1.76 \mathrm{~m}$ & 6 & 10000 & 6.00 \\
\hline
\end{tabular}

rectangular compound channels with only one critical depth. However, those non-dimensional plots are not general and limited to rectangular compound channels with channel width of 1.0 $\mathrm{m}$ and flood bank elevation of $1.0 \mathrm{~m}$. In this paper, general guidelines are presented to avoid the occurrence of multiple critical depths in a compound channel. If multiple critical depths are found to occur in a channel for a given discharge, then modifications in the geometry of compound channel are required to have only one critical depth. A convex curvature is forming in the curve as shown in figure $7 \mathrm{a}$ at the depth of flood bank elevation. It is observed that the convex curvature is cut by a vertical line at Froude number equal to one. To have a stable water surface profile for a given discharge, the convex curvature should be either pushed to left or to the right side of the vertical line $\left(F_{r}=1\right)$. Based on extensive numerical simulations, the following recommendations are made:

(i) There is a less possibility of multiple critical depths in a channel with flatter side slopes $\left(s_{m}\right)$. Therefore, decrease in the side slopes of the main channel. Vertical side slopes should be avoided. 


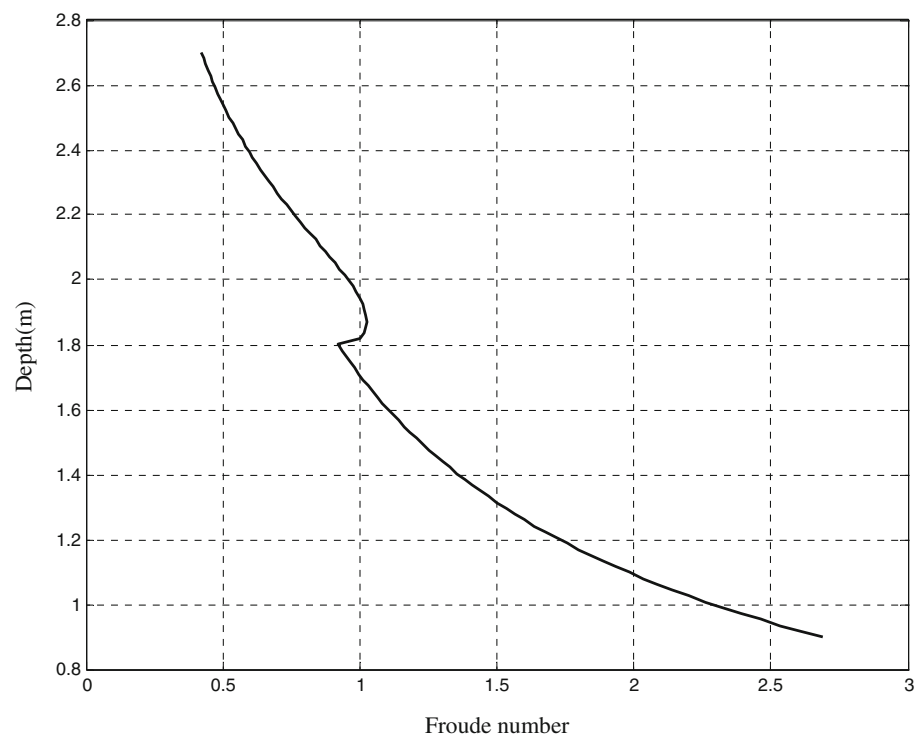

(a)

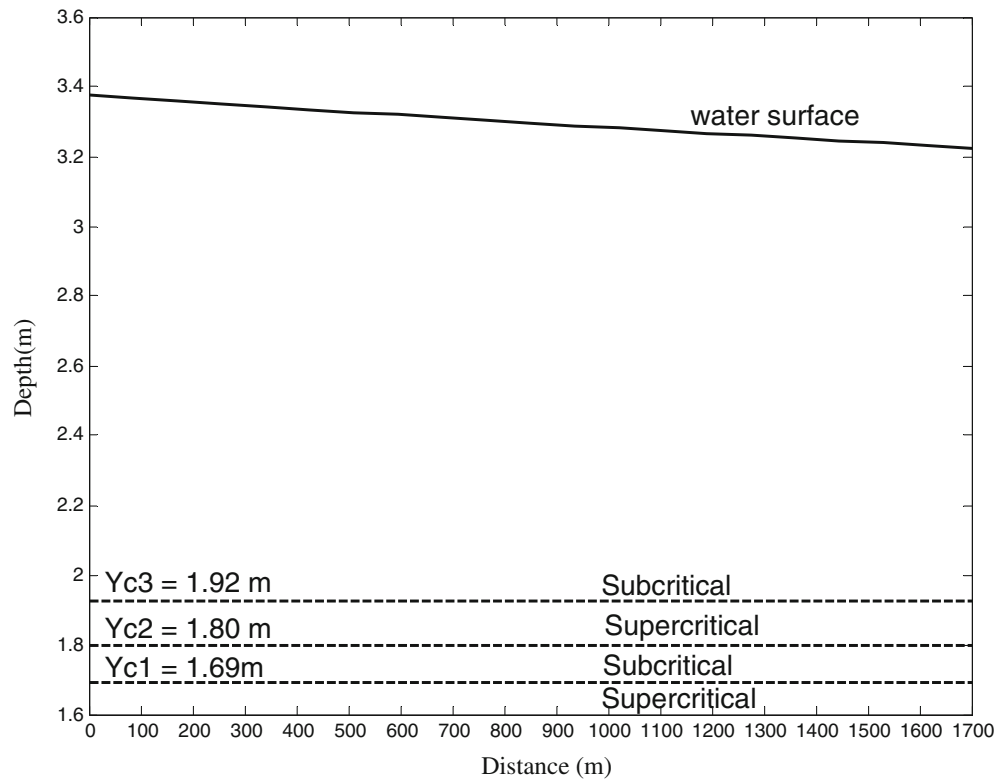

(b)

Figure 7. (a) Variation of the Froude number with depth and (b) water surface profiles for channel 4 of the tree-type network.

(ii) By increasing the flood bank elevation $(Z)$ the convex curvature (figure 7a) can be pushed higher on the side of lower Froude numbers.

(iii) By increasing the main channel width $\left(B_{m}\right)$, the maximum Froude number which can occur in a channel can be decreased. Therefore, pushing the entire curve ( $F_{r}$ vs depth) on to left hand side of the vertical line at $F_{r}=1$. 
Table 6. Changes in side slopes of main channels in tree type compound channel network.

\begin{tabular}{lcc}
\hline $\mathrm{i}$ & $\begin{array}{l}\text { Old side slope } \\
\text { of main channel }\end{array}$ & $\begin{array}{c}\text { New side slope } \\
\text { of main channel }\end{array}$ \\
\hline 3 & 1.5 & 2 \\
4 & 1 & 2 \\
5 & 1.5 & 2 \\
6 & 1 & 2 \\
7 & 1 & 2 \\
10 & 0.5 & 1 \\
11 & 0.5 & 1 \\
\hline
\end{tabular}

Table 7. Gradually varied flow computations in tree-type compound channel network with updated side slopes as given in table 6 .

\begin{tabular}{|c|c|c|c|c|}
\hline $\mathrm{i}$ & Discharge $\left(\mathrm{m}^{3} / \mathrm{s}\right)$ & $\mathrm{U} / \mathrm{S}$ depth $(\mathrm{m})$ & $\mathrm{D} / \mathrm{S}$ depth $(\mathrm{m})$ & Critical depth (m) \\
\hline 2 & 250.00 & $3.61(3.62)$ & 3.32 & $2.05(2.07)$ \\
\hline 3 & 138.24 & $3.32(3.32)$ & 3.25 & $1.93(1.94)$ \\
\hline 4 & 96.83 & $3.25(3.25)$ & 3.38 & $1.58(1.60)$ \\
\hline 5 & 25.91 & $3.38(3.38)$ & 3.58 & $1.44(1.43)$ \\
\hline 6 & 111.76 & $3.32(3.32)$ & 3.30 & $1.84(1.85)$ \\
\hline 7 & 69.23 & $3.30(3.31)$ & 3.39 & $1.73(1.74)$ \\
\hline 8 & 26.85 & $3.39(3.40)$ & 2.79 & $2.26(2.29)$ \\
\hline 9 & 16.90 & $2.13(2.13)$ & 1.66 & $1.14(1.14)$ \\
\hline 10 & 41.41 & $3.25(3.25)$ & 2.65 & $1.93(1.92)$ \\
\hline 11 & 25.31 & $2.65(2.66)$ & 2.06 & $1.74(1.76)$ \\
\hline 12 & 12.24 & $2.06(2.07)$ & 1.74 & $1.13(1.13)$ \\
\hline 13 & 70.93 & $3.38(3.38)$ & 3.22 & $2.12(2.16)$ \\
\hline 14 & 38.85 & $3.22(3.23)$ & 2.51 & $2.11(2.14)$ \\
\hline 15 & 17.24 & $2.51(2.51)$ & 2.62 & $1.23(1.24)$ \\
\hline 16 & 42.53 & $3.30(3.30)$ & 3.41 & $1.70(1.71)$ \\
\hline 17 & 25.26 & $3.41(3.43)$ & 2.47 & $2.32(2.35)$ \\
\hline 18 & 17.70 & $2.47(2.48)$ & 1.60 & $1.52(1.52)$ \\
\hline 19 & 9.95 & $2.13(2.13)$ & 2.10 & $1.06(1.07)$ \\
\hline 20 & 5.24 & $2.10(2.11)$ & 1.88 & $1.12(1.12)$ \\
\hline 21 & 42.38 & 3.39 (3.39) & 3.22 & $2.08(2.12)$ \\
\hline 22 & 21.22 & $3.22(3.22)$ & 3.06 & $2.02(2.05)$ \\
\hline 23 & 16.10 & $2.65(2.65)$ & 2.23 & $1.53(1.53)$ \\
\hline 24 & 9.54 & $2.23(2.24)$ & 2.01 & $1.22(1.22)$ \\
\hline 25 & 4.86 & $2.01(2.01)$ & 1.36 & $1.04(1.05)$ \\
\hline 26 & 13.06 & $2.06(2.06)$ & 1.86 & $1.22(1.22)$ \\
\hline 27 & 8.30 & $1.86(1.86)$ & 1.65 & $1.01(1.02)$ \\
\hline 28 & 5.92 & $1.65(1.64)$ & 1.48 & $0.88(0.89)$ \\
\hline 29 & 32.07 & $3.22(3.23)$ & 3.22 & $2.00(2.03)$ \\
\hline 30 & 15.99 & $3.22(3.22)$ & 3.33 & $1.78(1.81)$ \\
\hline 31 & 21.62 & $2.51(2.52)$ & 2.16 & $1.68(1.70)$ \\
\hline 32 & 14.53 & $2.16(2.16)$ & 1.87 & $1.39(1.39)$ \\
\hline 33 & 17.27 & $3.41(3.41)$ & 3.59 & $1.94(1.97)$ \\
\hline 34 & 7.55 & $2.47(2.47)$ & 1.71 & $1.40(1.41)$ \\
\hline
\end{tabular}


Table 7. (continued)

\begin{tabular}{lcccc}
\hline $\mathrm{i}$ & Discharge $\left(\mathrm{m}^{3} / \mathrm{s}\right)$ & $\mathrm{U} / \mathrm{S}$ depth $(\mathrm{m})$ & D/S depth $(\mathrm{m})$ & Critical depth $(\mathrm{m})$ \\
\hline 35 & 4.71 & $2.10(2.10)$ & 2.01 & $1.12(1.13)$ \\
36 & 21.16 & $3.22(3.23)$ & 2.98 & $2.14(2.15)$ \\
37 & 6.57 & $2.23(2.24)$ & 2.01 & $1.32(1.31)$ \\
38 & 4.67 & $2.01(2.01)$ & 1.47 & $1.13(1.13)$ \\
39 & 4.76 & $1.86(1.86)$ & 1.37 & $1.16(1.16)$ \\
40 & 2.39 & $1.65(1.65)$ & 1.61 & $0.81(0.81)$ \\
41 & 16.08 & $3.22(3.22)$ & 3.42 & $1.80(1.80)$ \\
42 & 7.08 & $2.16(2.16)$ & 2.05 & $1.40(1.41)$ \\
\hline
\end{tabular}

For the tree-network as shown in figure 5, with the selected channel geometry presented in table 1 resulted in three critical depths $\left(Y_{c 1}, Y_{c 2}\right.$ and $\left.Y_{c 3}\right)$ for channel numbers $3,4,5,6,7,10$ and 11 as presented in table 3 . In table 6 , not steep new side slopes are presented for above mentioned channels. The resulting computed water surface profiles are presented in table 7 . This modification in side slopes of main channels results in only one critical depth for each and every channel in the network. The guideline described above can be adapted for design of compound channel networks in the field. HEC-RAS 4.1 computed upstream flow depth and critical depths with modified side slopes are also presented in brackets in table 7.

\section{Summary and conclusions}

In this study, an efficient methodology was developed to compute steady and subcritical flow in a tree-type or looped-channel network with compound cross sections. The simultaneous solution algorithm based on the Newton-Raphson method is implemented to solve gradually varied flows. This proposed methodology is applicable for modelling trapezoidal and compound channel networks. The equations and the solution algorithm are presented in detail to facilitate the application of the method by the practicing engineering community. Finally, the methodology is demonstrated on a large tree-type and a looped compound open channel network. An algorithm is presented to calculate all the possible critical depths for a given channel and discharge. Recommended modifications are presented to improve the stability of flow in a compound channel by avoiding multiple critical depths. Modifications in geometry of a compound channel to have only one critical depth is demonstrated on large tree-type network. The proposed methodology is robust, easily applicable and can be a useful tool to design, optimize and to analyse water surface profiles in complex open channel networks.

\section{Notations}

$z=$ Elevation of channel bottom above datum

$y=$ Flow depth

$\propto=$ Velocity weighting coefficients

$Q_{t}=$ Total discharge at a section

$g=$ Acceleration due to gravity

$A_{t}=$ Total flow area

$h_{e}=$ Energy headloss 
$\Delta x=$ Reach length

$\overline{S_{F}}=$ Average friction slope

$Q_{f}=$ Discharge in the left flood plain and also equal to discharge in the right flood bank

$Q_{m}=$ Discharge in the main channel

$A_{f}=$ Flow area of the left flood bank also equal to flow area of right flood bank

$A_{m}=$ Flow area of the main channel

$K=$ Conveyance of the flow in the subelement

$S_{F}=$ Friction slope of the flow in the subelement

$Q=$ Discharge in subelement

$K_{f}=$ Conveyance of the left flood bank and also equal to discharge in the right flood bank

$K_{m}=$ Conveyance of the main channel

$A=$ Flow area of the subelement

$R=$ Hydraulic radius of the subelement

$V=$ Average velocity

$F=$ Froude number

$n=$ Mannings roughness coefficient

$a=$ Velocity weighting coefficients divided by square of the flow area

$B=$ Top width of flow area

$B_{f}=$ Bottom width of the left flood bank and also equal to right flood bank

$B_{m}=$ Bottom width of the main channel

$Z=$ Invert level of flood plain from the channel bottom

$s=$ Side slope

$P=$ Perimeter

$k=$ Relaxation factor

$\propto=$ Energy coefficient

$\beta=$ Momentum coefficient

Subscripts 1 and 2 denotes the sections 1 and 2, respectively

Subscripts $f$ and $m$ denote the flood area and main channel section, respectively

Subscript $i$ denotes the channel number, $j$ denotes the section number and $k$ denotes the equation number

Subscript $B C$ refers to boundary condition and subscript $J$ refers to junctions.

\section{Appendix I. Partial derivatives of energy equation}

\section{Partial derivatives of energy equation}

For each energy equation, there are four non-zero partial derivatives, namely the partial derivatives with respect to flow depth and with respect to the discharge at the section under consideration as well as partial derivatives with respect to the corresponding variables for the adjacent section. Thus for an energy equation, $F_{i, k}$, between section $j$ and $j+1$ of channel $i$, the following non-zero partial derivatives are obtained.

$$
\frac{\partial F_{i, k}}{\partial y_{i, j}}=-1-\frac{\partial a_{1}}{\partial y_{i, j}} \frac{Q_{t_{i, j}^{2}}}{2 g}+\frac{\Delta x_{i}}{2} \frac{\partial S_{F_{i, j}}}{\partial y_{i, j}}
$$




$$
\begin{gathered}
\frac{\partial F_{i, k}}{\partial y_{i, j+1}}=1+\frac{\partial a_{2}}{\partial y_{i, j+1}} \frac{Q_{t_{i, j+1}^{2}}}{2 g}+\frac{\Delta x_{i}}{2} \frac{\partial S_{F_{i, j+1}}}{\partial y_{i, j+1}} \\
\frac{\partial F_{i, k}}{\partial Q_{t_{i, j}}}=-\frac{2 a_{1}}{2 g} Q_{t_{i, j}}+\frac{\Delta x_{i}}{2} \frac{\partial S_{F_{i, j}}}{\partial Q_{i, j}} \\
\frac{\partial F_{i, k}}{\partial Q_{t_{i, j+1}}}=-\frac{2 a_{2}}{2 g} Q_{t_{i, j+1}}+\frac{\Delta x_{i}}{2} \frac{\partial S_{F_{i, j+1}}}{\partial Q_{i, j+1}} \\
\frac{\partial S_{F_{i, j}}}{\partial Q_{i, j}}=\frac{2 Q_{t_{i, j}}}{K_{t_{i, j}}^{2}} \\
\frac{\partial S_{F_{i, j+1}}}{\partial Q_{i, j+1}}=\frac{2 Q_{t_{i, j+1}}}{K_{t_{i, j+1}}^{2}} .
\end{gathered}
$$

The following partial derivates of the terms $a$ and $S_{F}$ with respect to $y$ in Eqs. (A1) to (A4) are obtained by using the chain rule.

$$
\begin{gathered}
\frac{d a}{d y}=\frac{d a}{d A_{f}} \frac{d A_{f}}{d y}+\frac{d a}{d A_{m}} \frac{d A_{m}}{d y}+\frac{d a}{d R_{f}} \frac{d R_{f}}{d y}+\frac{d a}{d R_{m}} \frac{d R_{m}}{d y} \\
\frac{d S_{F}}{d y}=\frac{d S_{F}}{d A_{f}} \frac{d A_{f}}{d y}+\frac{d S_{F}}{d A_{m}} \frac{d A_{m}}{d y}+\frac{d S_{F}}{d R_{f}} \frac{d R_{f}}{d y}+\frac{d S_{F}}{d R_{m}} \frac{d R_{m}}{d y} .
\end{gathered}
$$

Expressions for individual terms in Eqs. (A7) and (A8) are presented below.

$$
\begin{gathered}
\frac{d A_{f}}{d y}=B_{f}+S_{f}(y-Z) \\
\frac{d A_{m}}{d y}=B_{m}+2 Z s_{m} \\
\frac{d R_{f}}{d y}=\frac{\sqrt{s_{f}^{2}+1}\left(\frac{s_{f}\left(Z^{2}+y^{2}\right)}{2}-s_{f} Z y\right)+B_{f}^{2}+B_{f} s_{f}(y-Z)}{P_{f^{2}}} \\
\frac{d R_{m}}{d y}=\frac{B_{m}+2 s_{m}}{P_{m}} \\
\frac{d S_{F}}{d A_{f}}=-\frac{4 Q_{t}^{2} R_{f}^{2 / 3}}{n_{m}\left(2 K_{f}+K_{m}\right)^{3}} \\
\frac{d S_{F}}{d A_{m}}=-\frac{2 Q_{t}^{2} R_{m}^{2 / 3}}{n_{m}\left(2 K_{f}+K_{m}\right)^{3}} \\
\frac{d S_{F}}{d R_{f}}=-\frac{8 A_{f} Q_{t}^{2}}{3 R_{f}^{1 / 3} n_{f}\left(2 K_{f}+K_{m}\right)^{3}} \\
-\frac{4 A_{m} Q_{t}^{2}}{3 R_{m}^{1 / 3} n_{m}\left(2 K_{f}+K_{m}\right)^{3}}
\end{gathered}
$$




$$
\begin{gathered}
\frac{d a}{d A_{f}}=-\frac{2 R_{f}^{2 / 3} n_{m}\left(4 A_{f} R_{f}^{2} n_{m}^{3}+3 A_{m} R_{m}^{2} n_{f}^{3}\right)-2 A_{m} R_{f}^{2} R_{m}^{2 / 3} n_{f} n_{m}^{3}}{\left(2 A_{f} R_{f}^{2 / 3} n_{m}+A_{m} R_{m}^{2 / 3} n_{f}\right)^{4}} \\
\frac{d a}{d A_{m}}=-\frac{2 R_{m}^{2 / 3} n_{f}\left(3 A_{f} R_{f}^{2} n_{m}^{3}+A_{m} R_{m}^{2} n_{f}^{3}\right)-2 A_{f} R_{f}^{2 / 3} R_{m}^{2} n_{m} n_{f}^{3}}{\left(2 A_{f} R_{f}^{2 / 3} n_{m}+A_{m} R_{m}^{2 / 3} n_{f}\right)^{4}} \\
\frac{d a}{d R_{f}}=-\frac{4 A_{f} A_{m} n_{f} n_{m}\left(R_{f} R_{m}^{2 / 3} n_{m}^{2}-\frac{R_{m}^{2} n_{f}^{2}}{R_{f}^{1 / 3}}\right)}{\left(2 A_{f} R_{f}^{2 / 3} n_{m}+A_{m} R_{m}^{2 / 3} n_{f}\right)^{4}} \\
\frac{d a}{d R_{m}}=-\frac{4 A_{f} A_{m} n_{f} n_{m}\left(R_{m} R_{f}^{2 / 3} n_{f}^{2}-\frac{R_{f}^{2} n_{m}^{2}}{R_{m}^{1 / 3}}\right)}{\left(2 A_{f} R_{f}^{2 / 3} n_{m}+A_{m} R_{m}^{2 / 3} n_{f}\right)^{4}} .
\end{gathered}
$$

Numerical experimentation revealed that $2 A_{m} R_{f}^{2} R_{m}^{2 / 3} n_{f} n_{m}^{3}$ can be neglected without compromising the accuracy of the computations.

\section{Partial derivatives of continuity equation}

Here, the subscript $k$ refers to the equation number and its value is not identical to that of $j$. Likewise for the continuity equation $F_{i, k+1}$, the only non-zero partial derivatives are those with respect to the discharges of the adjacent sections, i.e.,

$$
\frac{\partial F_{i, k+1}}{\partial Q_{t_{i, j}}}=1 ; \frac{\partial F_{i, k+1}}{\partial Q_{t_{i, j+1}}}=-1
$$

\section{Partial derivatives of junction equations}

The Partial derivatives at junction of two upstream channels and one downstream channel are given as following.

$$
\frac{\partial F_{J 1,1}}{\partial Q_{t_{i+1,1}}}=-1 ; \frac{\partial F_{J 1,1}}{\partial Q_{t_{i+2,1}}}=-1 ; \frac{\partial F_{J 1,2}}{\partial Q_{t_{i+1,1}}}=-1 ; \frac{\partial F_{J 1,2}}{\partial y_{i, N_{i}+1}}=-1 ; \frac{\partial F_{J 1,3}}{\partial y_{i+2,1}}=-1 ; \frac{\partial F_{J 1,3}}{\partial y_{i, N_{i}+1}}=-1 .
$$

Similarly, partial derivatives at junction of one upstream channel and two downstream channel and junction of two series channels can be derived.

\section{Partial derivatives of boundary conditions}

The partial derivatives of boundary conditions for one upstream channel and two downstream channels may be written as

$$
\frac{\partial F_{B C, 1}}{\partial Q_{t_{i, 1}}}=-1 ; \frac{\partial F_{B C, 2}}{\partial y_{i+1, N_{i+1}+1}}=-1 ; \frac{\partial F_{B C, 3}}{\partial y_{i+2, N_{i+2}+1}}=-1
$$


Similarly, partial derivatives may be written for single inlet and single outlet channel or any other combination of boundary conditions.

\section{References}

Ackers P 1993 Flow formulae for straight two-stage channels. J. Hydraul. Res. 31(4): 509-531

Bhattacharjya R K 2006 Optimal design of open channel section incorporating critical flow condition. J. Irrig. Drain. Eng. 132(5): 513-518

Blalock M E and Sturm T W 1981 Minimum specific energy in compound open channel. J. Hydraulics Division ASCE 107(HY6): 699-717

Blalock M E and Sturm T W 1983 Closure of minimum specific energy in compound open channel. J. Hydraulics Division ASCE 109(HY3): 483-486

Bousmar D and Zech Y 1999 Momentum transfer for practical flow computation in compound channels. J. Hydraul. Eng. 125(7): 696-706

Brunner G W 2010 HEC-RAS river analysis system user's manual, version 4.1, Hydrologic Engineering Center, Institute For Water Resources, U. S. Army Corps of Engineers, Davis, Calif

Chaudhry M H 2008 Open channel flow, Second edition, New York: Springer, 10013, USA

Chaudhry M H and Schulte A 1986a Computation of steady state, gradually varied flows in parallel channels. Can. J. Civ. Eng. 13(1): 39-45

Chaudhry M H and Schulte A 1986b Simultaneous solution algorithm for channel network modeling. Water Resour. Res. 29(2): 321-328

Chaudhry M H and Bhallamudi S M 1988 Computation of critical depth in symmetrical compound channels. J. Hydraulic Res. 26(4): 377-396

Chow V T 1959 Open channel Hydraulics. New York: McGraw-Hill

Knight D W and Demetriou J D 1983 Floodplain and main channel flow interaction. J. Hydraul. Eng. 109(8): 1073-1092

Kordi E, Ahmadi M Z, Ayyoubzadeh S A and Zahiri A 2009 Prediction of the lateral flow regime and critical depth in compound open channels. Can. J. Civ. Eng. 36: 1-13

Kutija V 1995 A generalized method for the solution of flows in networks. J. Hydraul. Res. 33(4): 535-555

Naidu B J, Bhallamudi S M and Narasimhan S 1997 GVF computation in tree-type channel networks. J. Hydraul. Eng. 123(8): 700-708

Patankar S V 1980 Numerical heat transfer and fluid flow. New York: McGraw-Hill

Reddy H P and Bhallamudi S M 2004 Gradually varied flow computation in cyclic looped channel networks. J. Irrig. Drain. Eng. 130(5): 424-431

Schulte A M and Chaudhry M H 1987 Gradually varied flows in open channel networks. J. Hydraul. Res. 25(3): 357-371

Sen D J and Garg N K 2002 Efficient algorithm for gradually varied flows in channel networks. J. Irrig. Drain. Eng. 128(6): 351-357

Sturm T W and Sadiq A 1996 Water surface profiles in compound channel with multiple critical depths. J. Hydraul. Eng. ASCE 122(10): 703-709

Wylie E B 1972 Water surface profiles in divided channels. J. Hydraul. Res. 10(3): 325-341

Zhang Ming-liang and Shen Yong-ming 2007 Study and application of steady flow and unsteady flow mathematical model for channel networks. J. Hydrodynamics 19(5): 572-578 